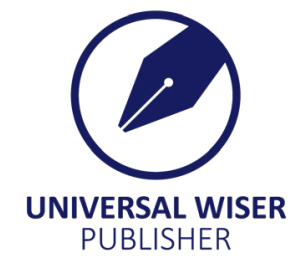

\title{
Some Experimental Aspects of Grinding Soft Steel Under Different Machining Conditions
}

\author{
Mohammadjafar Hadad $^{1^{*}}$, Alireza Sharbati ${ }^{2}$ \\ ${ }^{1}$ School of Mechanical Engineering, College of Engineering, University of Tehran, Tehran, Iran \\ ${ }^{2}$ Manufacturing Group, Mechanical Engineering Department, Amirkabir University of Technology (AUT), Tehran, Iran \\ "Email: mjhadad@ut.ac.ir
}

\begin{abstract}
In this study, the effects of dressing parameters, wheel topography and machining environment on grinding performance of soft steel are investigated. To generate different grinding wheel topographies, dressing speed and depth have been changed during dressing of vitrified $\mathrm{Al}_{2} \mathrm{O}_{3}$ wheels using single point diamond dresser. After dressing of grinding wheels, machining tests have been conducted to study the influence of the wheel topography and coolant-lubricant types on the performance of grinding operation. The results suggest that MQL is more suited to grinding of soft material in the finishing step (shallow cut) with the finest dressing than wet and dry grinding.
\end{abstract}

Keywords: MQL grinding, grinding forces, surface quality, wheel topography, environmentally friendly grinding

\section{Introduction}

The grinding processes performance is defined significantly by the grinding wheel preparation. Besides the required grinding wheel profile the dressing process must produce appropriate wheel topography ${ }^{[1-5]}$. The tool topography influences the workpiece surface roughness and surface morphology by the number and shape of the kinematical edges, the pore volume and the wear behaviour of the abrasive layer. The dressing process should enable a grinding process as consistent as possible taking into consideration the grinding wheel wear ${ }^{[6-12]}$. In the other hand, specific distributions of abrasive grains constitute the grinding wheel surface topography. The grinding wheel topography is one of the most important input variables of the grinding process ${ }^{[13,14]}$.

It is influenced by the wear during grinding process. In addition, active mechanisms of the dressing process are grit breakage or splintering, bonding breakage, grit break-out of the bonding, or grit deformation ${ }^{[15-18]}$. Despite the big influence of the dressing process on the grinding performance, its setup is often done empirically or theoretically on dry and wet grinding processes ${ }^{[16]}$. Malkin states a two-stage mechanism. Predominantly the abrasive grits break followed by breakage of the bonding ${ }^{[13]}$. Minke explains the material removal in dressing with stationary dressing tools by high dressing normal forces that destroy bonding bridges and break out grits and grit particles ${ }^{[19-23]}$. Marinescu et al. assume crack inducing in the abrasives ${ }^{[14]}$. Linke designed a holistic dressing process model for vitrified bonded grinding wheels ${ }^{[15]}$. The model enables a qualitative prognosis of the grinding wheel topography, the dressing forces and the thermal dressing process load $[15-17,19]$

Literature review shows the lack of study on the effects of grinding wheel surface topography on grinding performance in minimum quantity lubrication-MQL grinding. Tawakoli et al. ${ }^{[1]}$ and Rabiei et al. ${ }^{[1]}$ investigated the effects of the workpiece material hardness and grinding parameters on the MQL grinding process. Based on the results of their investigations, significant improvement can be achieved by MQL grinding of hardened steel in comparison to dry grinding process. In MQL grinding of $42 \mathrm{CrMo} 4$ soft steel, the surface roughness is higher than that in fluid cooling ${ }^{[1]}$. At lower removal rates $\left(\mathrm{a}_{\mathrm{e}}<10 \mu \mathrm{m}\right)$, surface finish and quality are the worst in comparison with dry and fluid grinding environments. Similar chip formation does not occur in $100 \mathrm{Cr} 6$ hardened steel because the chip formation is accomplished through a brittle fracture mechanism in brittle-hard materials ${ }^{[1]}$.

In order to improve MQL performance during grinding of soft steels, in this study, for the first time the effects of dressing parameters and wheel topography on MQL grinding performance are investigated. In other words, to generate different grinding wheel topographies, depth of dressing and dressing speed have been changed during dressing and 
conditioning of vitrified $\mathrm{Al}_{2} \mathrm{O}_{3}$ wheels using diamond dressers. After dressing of grinding wheels, machining tests have been conducted to study the influence of the wheel topography and coolant-lubricant types on the performance of grinding process. Performance indicators included: workpiece surface quality, grinding forces and wheel loading. The tests have been performed in presence of fluid, MQL with compressed air, MQL with argon, as well as, in dry conditions. In this paper, a precise definition of experimental set up is given (Section 2), followed by a results and discussion (Sections 3) as well as conclusions (Sections 4).

\section{Experimental Set Up}

Surface grinding experiments were conducted on MST-300-1000 universal surface grinder (manufactured by MST Company) using vitrified bond $\mathrm{Al}_{2} \mathrm{O}_{3}$ wheel. The workpiece was $\mathrm{St} 37$-soft steel $(83 \pm 3 \mathrm{HRB}$ ) with $65 \mathrm{~mm}$ length in grinding direction and $12 \mathrm{~mm}$ in width. Single point diamond dressing tool was used with access angle $\alpha_{\mathrm{d}}=10^{\circ}$ (Figure 1).

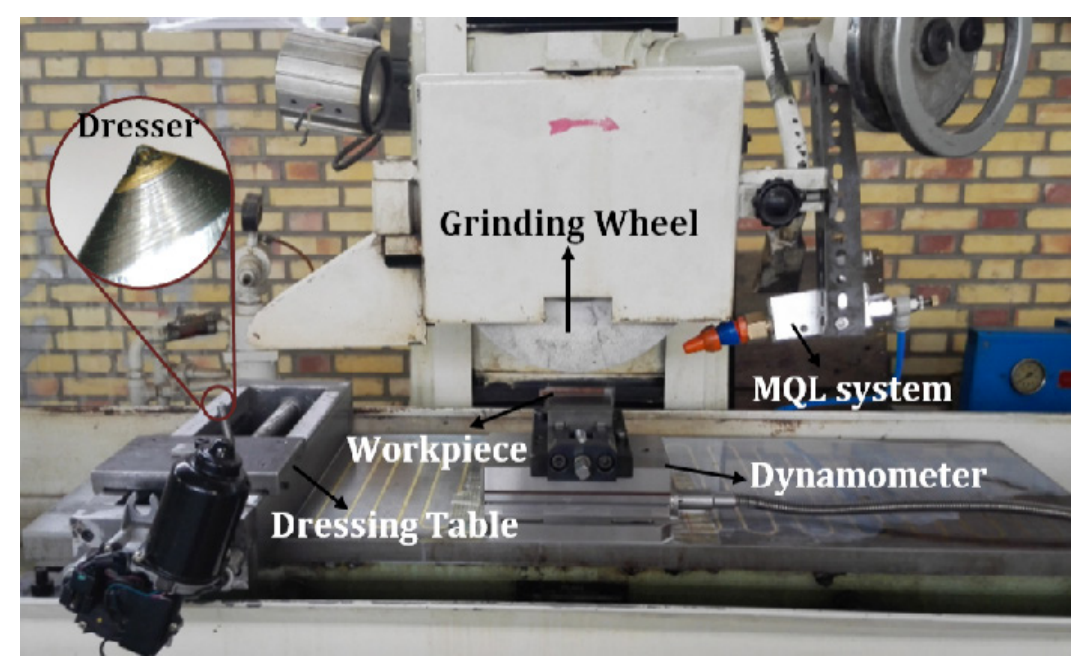

Figure 1. Experimental setup

The experimental setup is summarized in Table 1. The wheel was dressed three times (three passes) before each experiment with different dressing conditions as shown in Table 1.

The equipment utilized to control the minimum quantity of lubricant (MQL) was a homemade system in which creates the air envelope that served as the mixing chamber based on Venturi effect. The surface roughness and grinding forces measurements were performed after the 10th pass. The workpiece roughness was measured by Surface TesterTR200 (mobile roughness measurement) with a cut-off length of 0.8mm (according to DIN EN ISO 3274:1998). At the end of each test, $\mathrm{Ra}$ across the grinding direction was measured at five different points of ground surface. The grinding force components were recorded using a piezo-electric transducer based dynamometer (type Kistler 9257B) positioned under the workpiece clamping device (Figure 1). 
Table 1. Grinding conditions

\begin{tabular}{|c|c|}
\hline Grinding mode & Plunge surface grinding, down cut \\
\hline Grinding wheel & $\mathrm{Al}_{2} \mathrm{O}_{3}:$ AW60L5V28103 $\left(\mathrm{d}_{\mathrm{s}}=250 \mathrm{~mm}\right)$ \\
\hline Grinding machine & $\begin{array}{l}\text { MST-300-1000 universal surface grinder (manufactured by Machine Sazi } \\
\text { Tabriz Co.) }\end{array}$ \\
\hline Wheel speed $\left(\mathrm{V}_{\mathrm{c}}\right)$ & $\mathrm{V}_{\mathrm{c}}=26 \mathrm{~m} / \mathrm{s}$ \\
\hline Feed rate $\left(V_{f f}\right)$ & $\mathrm{V}_{\mathrm{ft}}=2500 \mathrm{~mm} / \mathrm{min}$ \\
\hline Depth of cut $\left(a_{e}\right)$ & $\mathrm{a}_{\mathrm{e}}=5 \mu \mathrm{m}$ \\
\hline Coolant-lubricant environments & Dry, Fluid (Wet), MQL with compressed air, MQL with argon, pure argon \\
\hline Conventional fluid grinding (Wet) & Water-miscible coolant lubricant at $5 \%$ concentration \\
\hline Conventional fluid flow rate & $18 \mathrm{lit} / \mathrm{hr}$ \\
\hline MQL oil & Vegetable oil \\
\hline Viscosity of MQL oil (at $20^{\circ} \mathrm{C}$ ) & $84 \mathrm{cP}$ \\
\hline MQL oil flow rate & $150 \mathrm{ml} / \mathrm{hr}$ \\
\hline MQL carrier gas & Compressed air, Argon \\
\hline Gas pressure in $\mathrm{MQL}$ & 4 bar \\
\hline Workpiece material & St37-soft steel with $83 \pm 3 \mathrm{HRB} ;(65 \mathrm{~mm} \times 12 \mathrm{~mm} \times 58 \mathrm{~mm})$ \\
\hline Dresser & Single point diamond \\
\hline Depth of each dressing pass $\left(a_{d}\right)$ & $\mathrm{a}_{\mathrm{d}}=3,15,30,45 \mu \mathrm{m}$ \\
\hline $\begin{array}{l}\text { Number of dressing passes }\left(\mathrm{N}_{\mathrm{dp}}\right) \text {, Total depth of } \\
\text { dressing }\left(\mathrm{a}_{\mathrm{dt}}\right)\end{array}$ & $\mathrm{N}_{\mathrm{dp}}=3, \mathrm{a}_{\mathrm{dt}}=9,45,90,135 \mu \mathrm{m}$ \\
\hline Dressing speed $\left(\mathrm{v}_{\mathrm{d}}\right)$ & $\mathrm{v}_{\mathrm{d}}=82,120,350,600 \mathrm{~mm} / \mathrm{min}$ \\
\hline Access angle $\left(\alpha_{d}\right)$ & $\alpha_{\mathrm{d}}=10^{\circ}$ \\
\hline
\end{tabular}

\section{Results and Discussion}

Wheel surface topographies generated by different dressing conditions are shown in Figure 2. According to Figure 2, when fine dressing is selected, the minimum impact energy is necessary to induce splintering effects at the abrasive grits. With this energy only elastic and plastic deformations of the grinding layer occur without splintering or break-out of the grits ${ }^{[16]}$.

Dressing with a high depth of cut tends to shatter the wheel structure, whereas a conditioning process with a small depth of dressing cut has likely more friction contacts with higher heat generated because of the increasing grit collision frequency between wheel grit and dressing diamond. This assumption was proven by a higher proportion of grit break-outs at the expense of grit breakages after dressing with higher depth of cut ${ }^{[13-17]}$. 

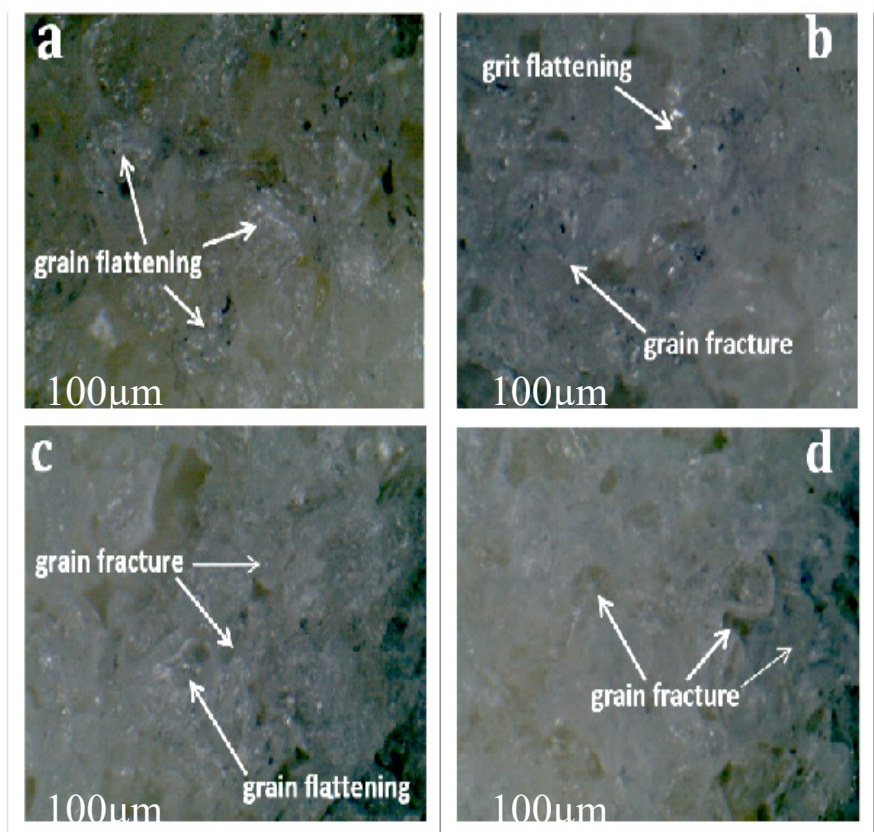

Figure 2. Wheel surface topography (magnification: $100 \times$ ) with; a) $a_{d}=3 \mu \mathrm{m}$ and $\left.v_{d}=120 \mathrm{~mm} / \mathrm{min}, b\right) a_{d}=3 \mu \mathrm{m}$ and $\left.v_{d}=600 \mathrm{~mm} / \mathrm{min}, c\right) a_{d}=45$ $\mu \mathrm{m}$ and $\left.v_{d}=120 \mathrm{~mm} / \mathrm{min}, d\right) a_{d}=45 \mu \mathrm{m}$ and $v_{d}=600 \mathrm{~mm} / \mathrm{min}$

In general, both grain fracture and plastic deformation play important roles. With finer dressing, localized plastic flow results in flattening and smoothing of some grain tips not fractured away. A similar effect is obtained by the addition of spark-out passes without incrementing the dressing depth ${ }^{[13,14]}$. Coarser dressing causes more grain fracture and a sharper wheel.

Figure 3 illustrates specific grinding forces (grinding force divided by the width of grinding) for different wheel topographies and coolant-lubricant types. According to the Figure 3a, the maximum specific tangential grinding force occurs during dry grinding process with $\mathrm{a}_{\mathrm{d}}=3 \mu \mathrm{m}$ and $\mathrm{v}_{\mathrm{d}}=120 \mathrm{~mm} / \mathrm{min}$. In this condition, workpiece surface was burned. Also, in these dressing conditions $\left(a_{d}=3 \mu \mathrm{m}\right.$ and $v_{d}=120 \mathrm{~mm} / \mathrm{min}$ ), specific tangential grinding force for wet grinding is near $1.66 \mathrm{~N} / \mathrm{mm}$, with workpiece surface burning, in which is maximum for wet grinding between other dressing speeds $\left(\mathrm{v}_{\mathrm{d}}=350 \mathrm{~mm} / \mathrm{min}\right.$ and $\left.\mathrm{v}_{\mathrm{d}}=600 \mathrm{~mm} / \mathrm{min}\right)$. MQL grinding with argon shows resultant forces similar to wet grinding, while the maximum force is measured at $\mathrm{a}_{\mathrm{d}}=3 \mu \mathrm{m}$ and $\mathrm{v}_{\mathrm{d}}=120 \mathrm{~mm} / \mathrm{min}$, but without workpiece surface burning. In this case, specific tangential grinding force is about $1.66 \mathrm{~N} / \mathrm{mm}$, thus MQL grinding with argon has better cooling performance. In addition, in these dressing conditions for MQL grinding with compressed air, the specific tangential grinding force is about 1.25 $\mathrm{N} / \mathrm{mm}$, while maximum specific tangential grinding force for MQL grinding with compressed air for different dressing speed is $1.66 \mathrm{~N} / \mathrm{mm}$. In $\mathrm{v}_{\mathrm{d}}=350 \mathrm{~mm} / \mathrm{min}$, specific tangential grinding forces for dry, wet, MQL with argon are 3.16, 0.83, $0.83 \mathrm{~N} / \mathrm{mm}$, respectively. Also, it can be shown from Figure 3 that the lowest specific tangential grinding forces for four grinding conditions occur at $\mathrm{v}_{\mathrm{d}}=600 \mathrm{~mm} / \mathrm{min}(1.41,0.58,0.41,0.41 \mathrm{~N} / \mathrm{mm}$ for dry, wet, MQL with compressed air, MQL with argon, respectively). This clearly demonstrates that, MQL system was able to penetrate into the region of contact between the grinding wheel and the workpiece more effectively than fluid cooling. It is clear that the coolant-lubricant in the grinding process influences the chip formation process by building up a lubricant film, thus lowering the friction forces, and cooling the contact zone. As the lubrication effect increases, there is a corresponding increase inelastic-plastic deformation under the cutting edge of the abrasive grain, resulting in a decrease in workpiece roughness. By reducing friction forces, friction heat and therefore the total process heat are reduced ${ }^{[1]}$. During dressing of conventional wheels with a single-point diamond tool, the dresser follows a path which would appear to be like thread (fractured grooves) on the abrasive grains ${ }^{[3,4]}$.

Coarser dressing causes more grain fracture and sharp wheel and consequently less contact area between the grain and workpiece in the grinding zone (Figure 3). Therefore, dressing process (specially dressing speed) has significant effect on the MQL oil mist performance in the grinding process that must be considered to optimize MQL grinding. In Figures $3 b$ and $3 \mathrm{c}, \mathrm{MQL}$ grinding with argon has minimum tangential forces. This proves that atomized oil carried with argon is more effective in the contact zone in comparison to other conditions. It can be demonstrated from Figure $3 \mathrm{~d}$ that forces reduce 
rather than grinding with fine wheels.

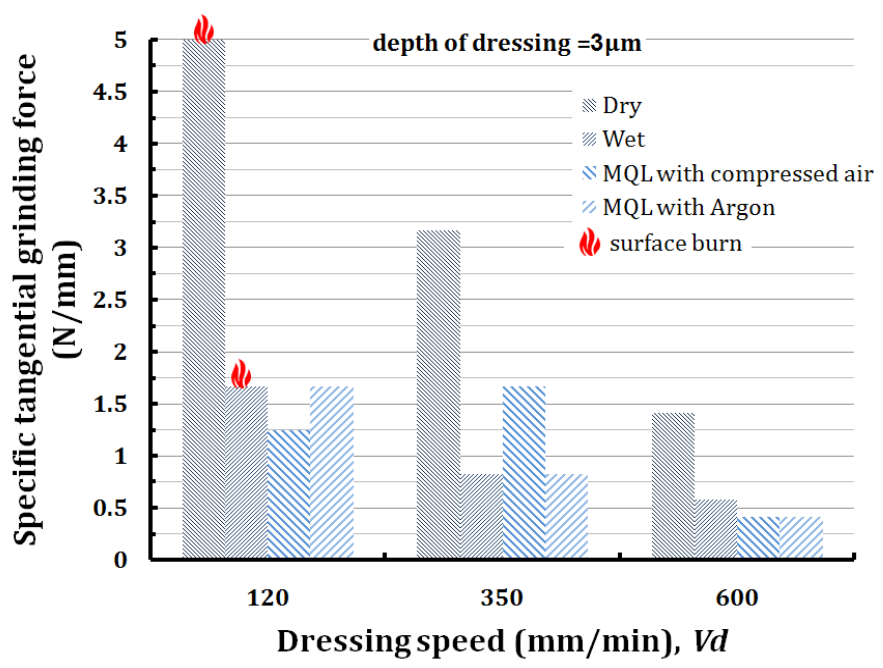

a

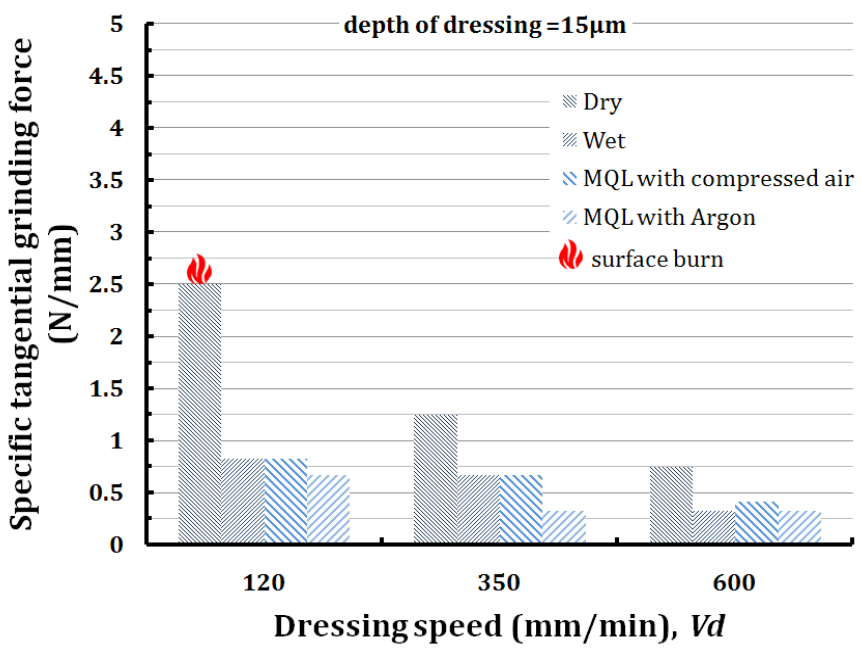

b

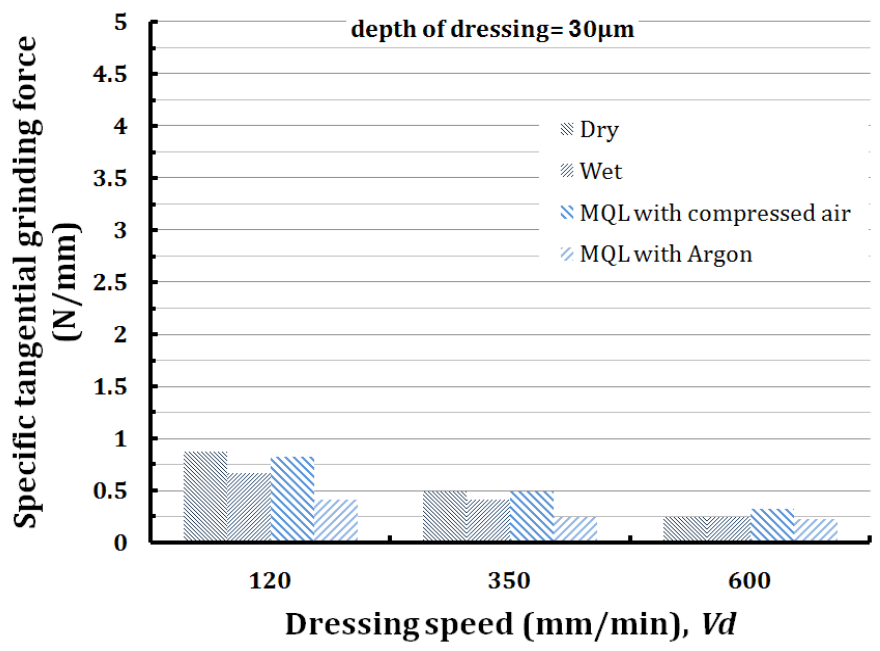

C 


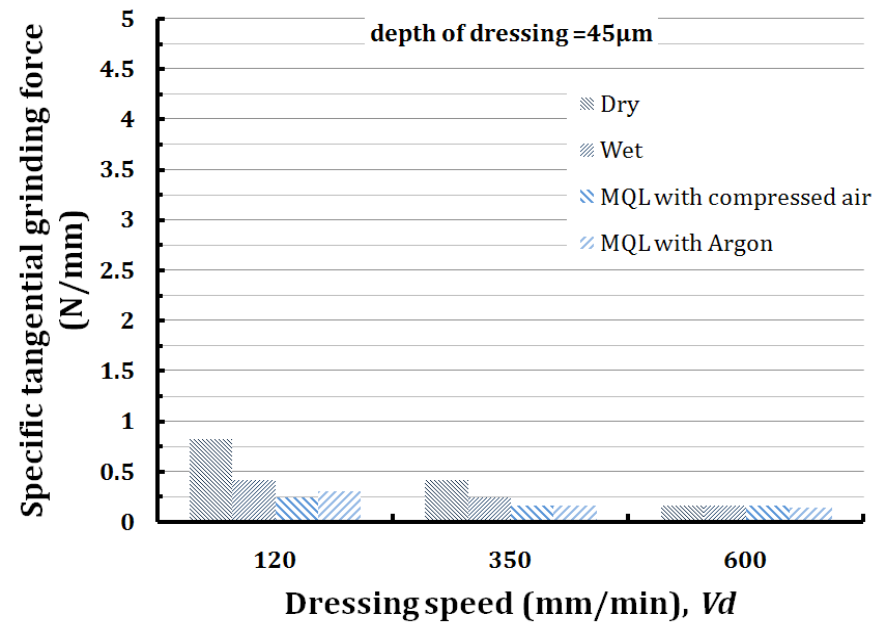

d

Figure 3. Specific tangential grinding force vs. dressing speed for different depths of dressing as: a) $3 \mu \mathrm{m}, \mathrm{b}) 15 \mu \mathrm{m}, \mathrm{c}) 30 \mu \mathrm{m}$ and d) $45 \mu \mathrm{m}$; $\left(V_{\mathrm{c}}=26 \mathrm{~m} / \mathrm{s}, \mathrm{V}_{\mathrm{ft}}=2500 \mathrm{~mm} / \mathrm{min}, \mathrm{a}_{\mathrm{e}}=5 \mu \mathrm{m}\right)$

In the case of grinding with coarse dressed wheels, the number of the active grains per unit area decreases that result in lower grinding forces. In coarser dressed wheel topography (low grinding forces), the process shows less sensitivity to the type of the coolant-lubricant as can be demonstrated from comparing Figures $3 \mathrm{a}$ and $3 \mathrm{~d}$. While a better surface finish can be produced by resorting to finer dressing conditions, this will cause the wheel to be duller, thereby raising the grinding power and specific energy and increasing the risk of thermal damage ${ }^{[13]}$. This behaviour is illustrated in Figure 4 which shows a trade-off between specific energy and surface roughness as the dressing severity is varied for otherwise identical grinding conditions ${ }^{[13]}$. In this case, changing only the dressing severity caused as much as a fivefold variation in surface roughness and specific energy. It is of interest to note that the results for all coolant-lubricant types fall on the same tradeoff curve. Again in case of coarser dressed wheel topography, the process shows less sensitivity to the type of the coolantlubricant as can be demonstrated from comparing Figures $4 \mathrm{a}$ and $4 \mathrm{~d}$. It can be seen that the plot of specific energy versus surface roughness yields a straight line in which its slope is steeper for finer dressed wheels. In other words, roughness changes (Rate of change of the roughness) is near the tangential force alternations when depth of dressing is small (finer dressing conditions with $\mathrm{a}_{\mathrm{d}}=3 \mu \mathrm{m}$ ).

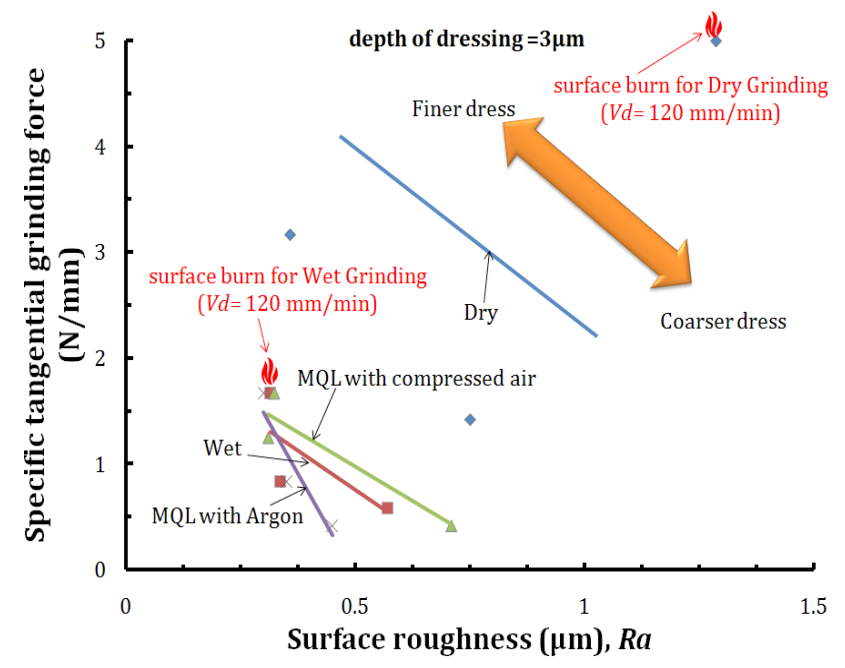

a 


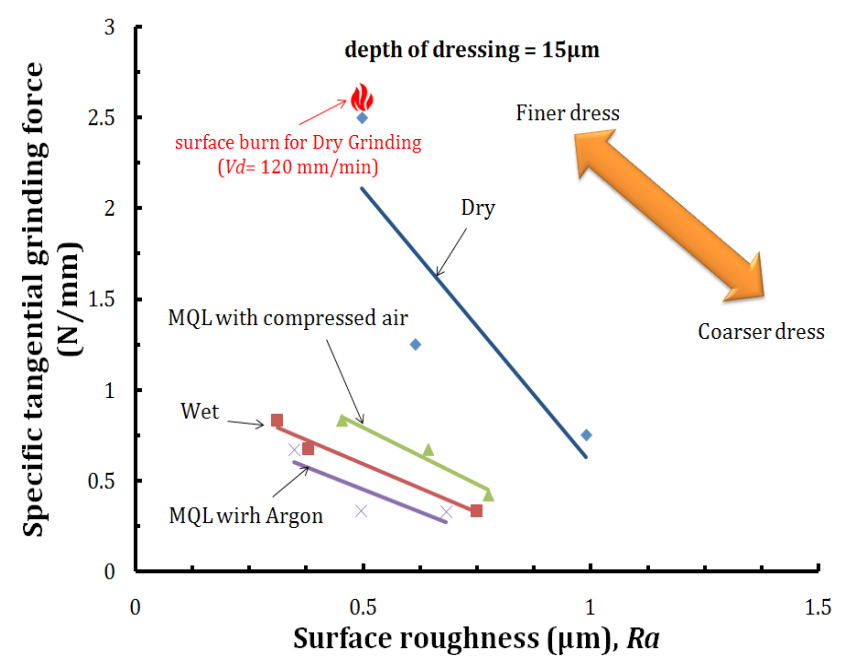

b

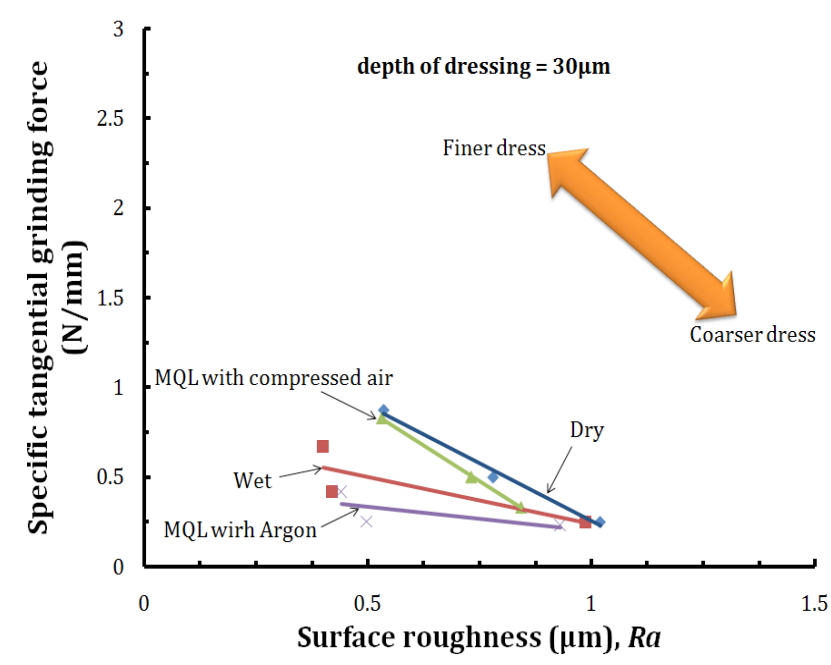

C

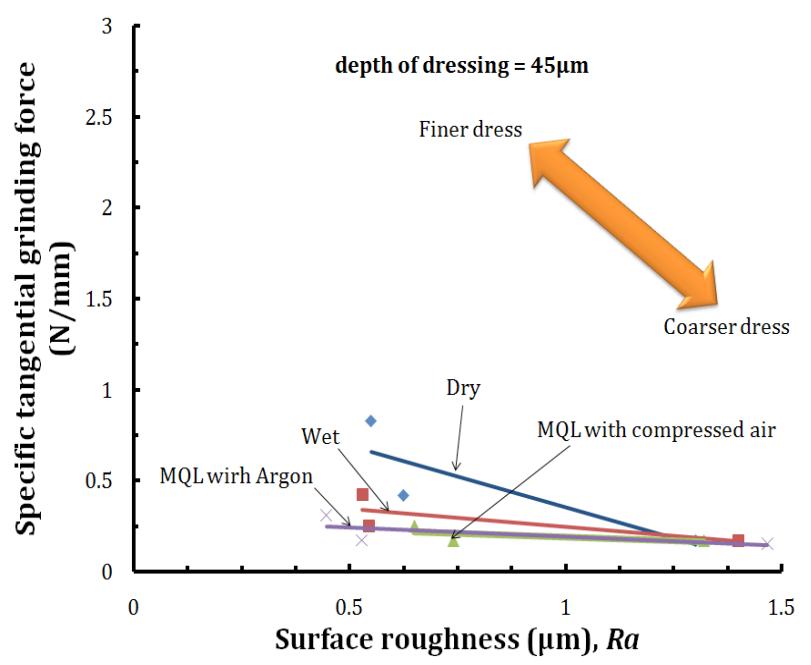

Figure 4. Specific tangential grinding force vs. surface roughness for different depths of dressing as: a) $3 \mu \mathrm{m}$, b) $15 \mu \mathrm{m}$, c) $30 \mu \mathrm{m}$ and d) 45 $\mu \mathrm{m} ;(\mathrm{Vc}=26 \mathrm{~m} / \mathrm{s}, \mathrm{Vft}=\mathbf{2 5 0 0} \mathrm{mm} / \mathrm{min}, \mathrm{ae}=5 \mu \mathrm{m})$

As discussed in $[1,11]$, in MQL grinding of soft steels, surface roughness and quality are the worst in comparison to fluid cooling and even dry conditions, especially in grinding processes with small depth of cuts $\left(a_{e}<10 \mu m\right)$. Due to lower surface quality, soft steels can be a limitation for MQL technique. But, Figure 4 shows that in order to improve of surface roughness in soft steels with MQL technique, in each depth of dressing value, increasing dressing speeds result 
in optimization (minimization) of surface roughness in comparison to dry and wet grinding. In these conditions, using the finest grinding wheels dressed with $\mathrm{v}_{\mathrm{d}}<400 \mathrm{~mm} / \mathrm{min}$ and $\mathrm{ad}=3 \mu \mathrm{m}$ result in better surface roughness (without surface burn) for MQL grinding in comparison to fluid cooling and dry conditions (with surface burn).

The better surface roughness values employing finer dressed wheels can be explained by dulling of the grits. The dull grits and a film of MQL oil between the grit wear flat area and workpiece surface smooth the surface on the one hand and enlarge the deformation zone in the contact area on the other hand. In addition, in these conditions, MQL grinding with argon have better surface quality in comparison to MQL grinding with compressed air. These results suggest that MQL is more suited to grinding of soft material in shallow cut with the finest dressing than wet and dry grinding. In addition, lower force ratio in MQL case, suggests MQL is as strongly sensitive to changes in conditions as wet and dry. In case of coarser dressed wheel topographies $\left(\mathrm{v}_{\mathrm{d}}<400 \mathrm{~mm} / \mathrm{min}\right.$ and $\left.\mathrm{a}_{\mathrm{d}}=45 \mu \mathrm{m}\right)$, the process shows less sensitivity to the type of the coolantlubricant as can be demonstrated from comparing Figures 4a-d.

During MQL grinding of soft steel, lower surface quality in finer dressed wheel topography (dressed with lower dressing speed) is resulted (Figures $4 \mathrm{~b}, \mathrm{c}, \mathrm{d}$ ). When the finer dressed wheel is used, normal forces resulted from MQL are higher than those from dry and fluid grinding. The reason is higher grain-related normal forces and a higher number of kinematic cutting edges due to increased plastic deformation (because of dulling of the grits during fine dressing). During grinding, the cutting edge of the grain penetrates the workpiece on a very flat path causing plastic flow of the material after a very short phase of the elastic deformation ${ }^{[1]}$. Since the angle between the cutting edge contour and the workpiece surface is very small due to the cutting edge rounding, no chip is formed initially. The workpiece material is only thrust a side, forms material outbursts or side ridges (called side flow), and flows to the flank underneath the cutting edge ${ }^{[12,15]}$. Only if the cutting edge penetrates the workpiece to a depth that the undeformed chip thickness, $h_{c u}$, equals the critical cutting depth, $\mathrm{T}_{\mu}$, does the actual chip formation begin (Figure 5).
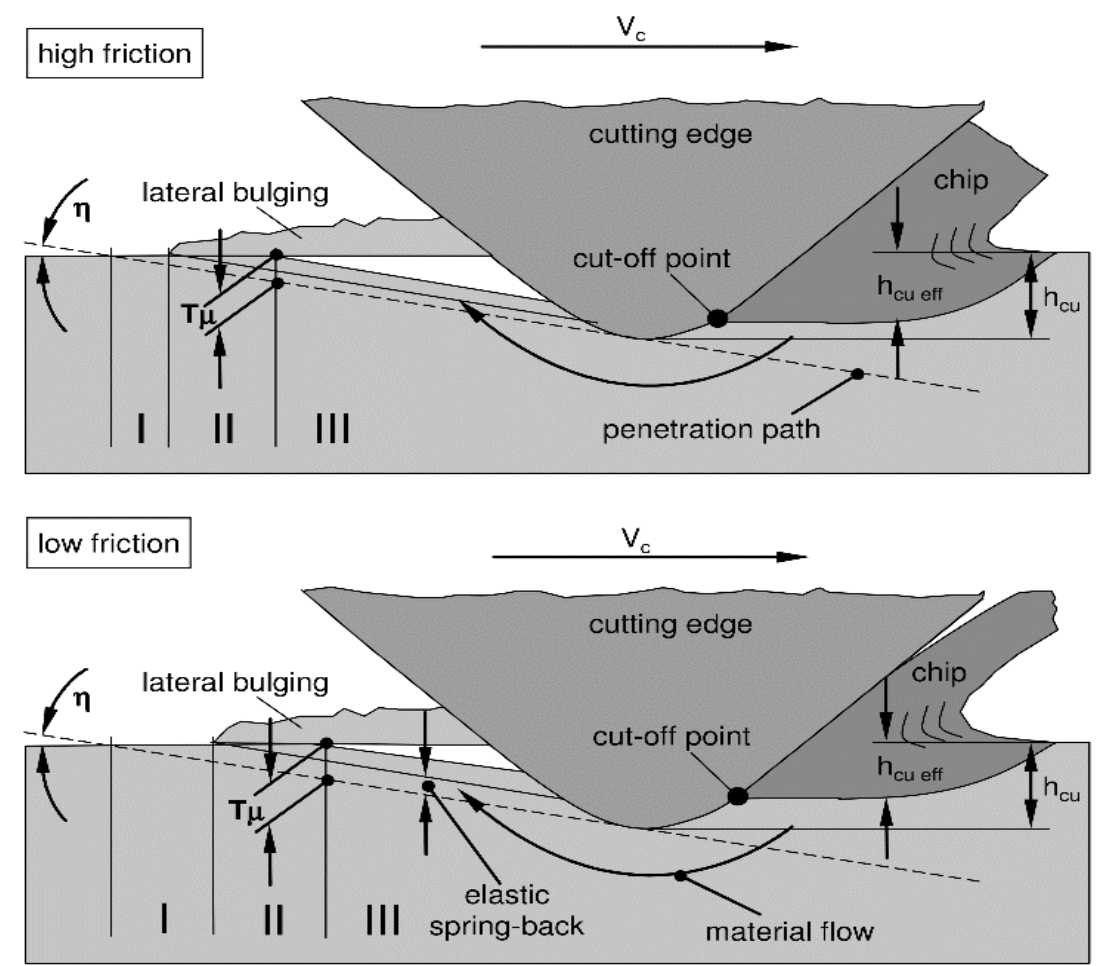

Figure 5. The influence of friction on the cutting depth and machining efficiency ${ }^{[14]}$

Since displacement processes and chip formation occur simultaneously in the further process, it is crucial for the efficiency of the material removal how much of the uncut chip thickness, hcu, is actually removed as chip, and what the effective chip thickness, hcu,eff, is. If the friction is increased, the critical cutting depth decreases, which is additionally influenced by the radius of the cutting edge of the grain ${ }^{[1,14]}$. Improved lubrication increases the plastic deformation toward a higher critical cutting depth. Thus, there is a reduction in friction between the active partners. With constant uncut chip thickness, hcu, the effective chip thickness, hcu,eff (thickness of the formed chip), decreases simultaneously with a reduction in friction ${ }^{[1,12-14]}$. At lower removal rates, surface finish and quality are the worst in comparison with other 
grinding environments. Only few grains that are large enough can penetrate into the workpiece to a depth that undeformed chip thickness equals the critical cutting depth for actual cutting formation. By applying MQL, lubrication and the critical cutting depth were increased causing lower thickness of the formed chip. In this case, smaller grains generate uncut chips on the ground surface (Figure 6).

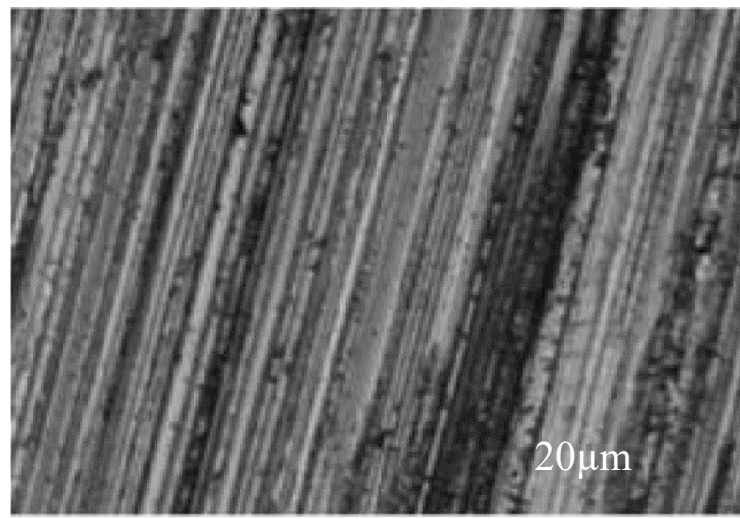

Figure 6. Surface morphology of MQL of $42 \mathrm{CrMo4}$ soft steel under $V_{\mathrm{ft}}=2.5 \mathrm{~m} / \mathrm{min}, \mathrm{V}_{\mathrm{c}}=25 \mathrm{~m} / \mathrm{s}, \mathrm{a}_{\mathrm{e}}=5 \mu \mathrm{m}$ (magnification: $\left.1000 \times\right)^{[1]}$

Using coarser dressed wheel topography (Figure 4) as well as higher grinding material removal rates (Figure 7), which leads to an increase in the penetration of each grain in the workpiece in the contact zone, lower plowing and side flow left on the ground surface and consequently the lower surface roughness can be observed in the MQL grinding compare to the dry grinding (Figure 4).

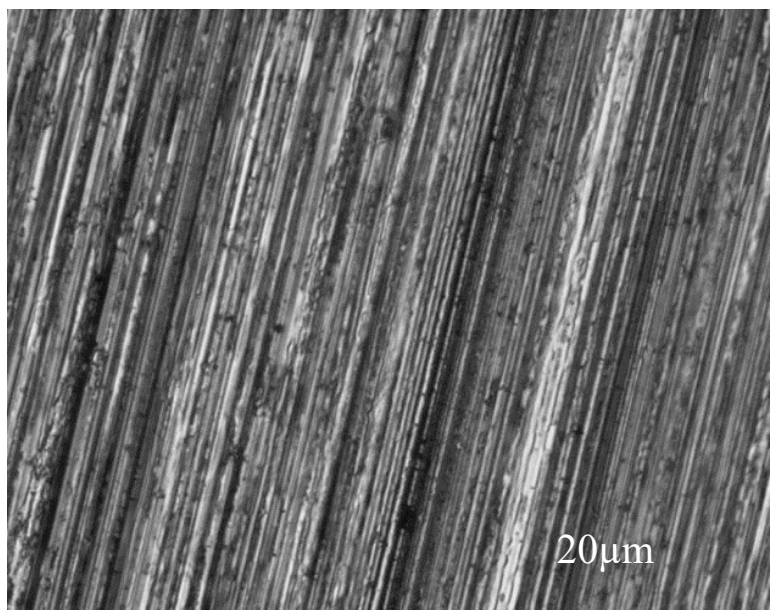

Figure 7. Surface morphology of MQL grinding of $42 \mathrm{CrMo4}$ soft steel under $\mathrm{V}_{\mathrm{ft}}=\mathbf{2 . 5} \mathrm{m} / \mathrm{min}, \mathrm{V}_{\mathrm{c}}=\mathbf{3 0} \mathrm{m} / \mathrm{s}, \mathrm{a}_{\mathrm{e}}=\mathbf{2 5 \mu \mathrm { m }}(\text { magnification: } 1000 \times)^{[1]}$

\section{Conclusions}

1. The cutting efficiency in MQL grinding of soft steel is due to largely combined effects of lubrication and appropriateness of the wheel and workpiece combinations.

2. With fine dressing, localizes plastic flow results in flattening and smoothing of some grain tips not fractured away. Coarse dressing causes more grain fracture and a sharper wheel so it generally results in lower grinding forces and higher surface roughness, whereas fine dressing leads to higher forces and better surface finish. Also, the dressing speed is found to have significant influences on the grinding performance compare to depth of dressing.

3. The results suggest that MQL is more suited to grinding of soft material in the finishing step (shallow cut) with the finest dressing than wet and dry grinding. 


\section{Conflict of interest}

The authors declare no conflict of interest.

\section{References}

[1] Tawakoli T, Hadad MJ, Sadeghi MH, Daneshi A, Stöckert S, Rasifard A. An experimental investigation of the effects of workpiece and grinding parameters on minimum quantity lubrication-MQL grinding. International Journal of Machine Tools \& Manufacture 2009; 49: 924-932.

[2] Tawakoli T, Hadad MH, Sadeghi MH. Influence of oil mist parameters on minimum quantity lubrication-MQL grinding process. International Journal of Machine Tools \& Manufacture 2010; 50: 521-531.

[3] Tawakoli T, Hadad MJ, Sadeghi MH. Investigation on minimum quantity lubricant-MQL grinding of $100 \mathrm{Cr} 6 \mathrm{hardened}$ steel using different abrasive and coolant-lubricant types. International Journal of Machine Tools \& Manufacture 2010; 50: 698-708.

[4] Tawakoli T, Hadad MJ, Sadeghi MH, Daneshi A, Sadeghi B. Minimum quantity lubrication in grinding: effects of abrasive and coolant-lubricant types. Journal of Cleaner Production 2011; 19: 2088-2099.

[5] Sadeghi MH, Hadad MJ, Tawakoli T, Vesali A, Emami M. An investigation on surface grinding of AISI 4140 hardened steel using minimum quantity lubrication-MQL technique. International Journal of Material Forming 2010; 3: 241-251.

[6] Sadeghi MH, Haddad MJ, Tawakoli T, Emami M. Minimal quantity lubrication-MQL in grinding of Ti-6Al-4V titanium alloy. International Journal of Advanced Manufacturing Technology 2009; 44: 487-500.

[7] Tawakoli T, Hadad MJ, Daneshi A, Sadeghi MH, Sadeghi B. Study on the effects of abrasive and coolant-lubricant types on minimum quantity lubrication-MQL grinding. Advanced Materials Research 2011; 325: 231-237.

[8] Hadad MJ, Tawakoli T, Sadeghi MH, Sadeghi B. Temperature and energy partition in minimum quantity lubricationMQL grinding process. International Journal of Machine Tools \& Manufacture 2012; 54-55: 10-17.

[9] Hadad MJ. Minimum quantity lubrication-MQL grinding process \& investigation of surface quality.” Ph.D. Thesis. Manufacturing Engineering Division, School of Engineering, Tarbiat Modares University; Tehran; Iran; 2010.

[10] Hadad MJ, Sadeghi B. Thermal analysis of minimum quantity lubrication-MQL grinding process. International Journal of Machine Tools \& Manufacture 2012; 63: 1-15.

[11] Rabiei F, Rahimi AR, Hadad MJ, Ashrafijou M. Performance improvement of MQL technique in surface grinding by simulation and optimizing. Journal of Cleaner Production 2015; 86: 447-460.

[12] Dixit US, Sarma DK, Davim JP. Environmentally friendly machining. Springer-Verlag, New York; USA; 2012.

[13] Malkin D, Guo C. Grinding technology: theory and applications of machining with abrasives. 2nd Edition. Industrial Press Inc. New York; USA; 2008.

[14] Klocke EHF. Manufacturing Process 2: Grinding, Honning, Lapping. RWTH ed.; ISBN: 978-3-540-92258-2; 2009.

[15] Linke B. Wirkmechanismen beim Abrichten keramisch gebundener Schleifscheiben. Doctoral thesis; Aachen University; 2007.

[16] Linke B. Dressing process model for vitrified bonded grinding wheels. CIRP Annals-Manufacturing Technology 2008; 57: 345-348.

[17] Linke B, Klocke F. Temperatures and wear mechanisms in dressing of vitrified bonded grinding wheels. International Journal of Machine Tools \& Manufacture 2010; 50: 552-558.

[18] Wimmer J. Konditionieren hochharter Schleifscheiben zum Schleifen von Hochleistungskeramik. Doctoral Thesis; University of Kaiserslautern; 1995.

[19] Liebe I. Auswahl und Konditionierung von Werkzeugen für das Außenrund-Profilschleifen technischer Keramiken. Doctoral Thesis; TU Berlin, Berlin; 1996

[20] Hadad MJ. An experimental investigation of the effects of machining parameters on environmentally friendly grinding process. Journal of Cleaner Production 2015; 108: 217-231.

[21] Minke E. Grundlagen der Verschleiss ausbildung an nicht-rotierenden Abrichtschneiden zum Einsatz an konventionellen Schleifwerkzeugen.” Doctoral Thesis; University of Bremen; Bremen, 1988.

[22] Kadivar M, Azarhoushang B, Shamray S, Krajnik P. The effect of dressing parameters on micro-grinding of titanium alloy. Precision Engineering 2018; 51: 176-185.

[23] Palmer J, Ghadbeigi H, Novovic D, Curtis D. An experimental study of the effects of dressing parameters on thetopography of grinding wheels during roller dressing. Journal of Manufacturing Processes 2018; 31: 348-355. 